\title{
Cancer of the Bladder in South East Nigeria: Epidemiological Patterns in a Low Resource Region

\author{
Obi Anselm $\mathrm{O}^{1^{*}}$ and Ogolo Donald $E^{2}$
}

${ }^{1}$ Associate Professor, Urology, Ebonyi State University and Consultant Urologist, Alex Ekwueme Federal University Teaching Hospital, Abakaliki, Nigeria

${ }^{2}$ Senior Registrar, Department of Surgery, Alex Ekwueme Federal University Teaching Hospital, Abakaliki, Nigeria; Macquarie University Hospital, Sydney, Australia

*Corresponding author: Dr Obi Anselm O, Associate Professor, Urology, Ebonyi State University and Consultant Urologist, Alex Ekwueme Federal University Teaching Hospital, Abakaliki, Nigeria

\begin{abstract}
Background: Bladder cancer $(\mathrm{CAB})$ is a urological malignancy that significantly contributes to morbidity and mortality, especially when detected late.

Aim: This study highlights the challenges of late presentation and changing histological trend of the condition in a low resource region. The objectives were to establish the relationship between demographic factors, and to elucidate some characteristics of histological patterns in our region.

Methods: A retrospective cohort study of all cases of bladder cancer seen at our facility between 2011 and 2015 was carried out utilizing data from patient case notes. Extracted data was analyzed using descriptive statistics.

Results: A total of 18 cases of histologically confirmed bladder cancer were reviewed-12 males (66.7\%) and 6 females $(33.3 \%)$, with a male to female ratio of $2: 1$. The patients were aged between 19 and 78 years. Majority were petty traders $(44 \%)$. Transitional cell carcinoma (TCCAB) was confirmed in 12 cases $(66.7 \%)$ and squamous cell cancer (SCCAB) in 6 cases $(33.3 \%)$. Majority of the cases of SCCAB were seen in patients below 30 years of age $(66.7 \%)$ while majority for TCCAB were above 50 years $(91.7 \%)$. The commonest presenting complaint was total, painless haematuria with associated clots $(77.8 \%)$ with average duration from time of onset to presentation at this facility of 2 months and 3 weeks for SCCAB and 17 months for TCCAB. Hemoglobin level at presentation was between 6-8 $\mathrm{g} / \mathrm{dl}$ in $44.4 \%$ of cases. Majority seen on abdominal ultrasound scan and cystoscopy were flat masses (61.1\%). Most cases were stage I for TCCAB (58.3\%) and stage II for SCCAB (83.3\%), while $11.1 \%$ were metastatic requiring chemotherapy. There was one case of recurrence (stage II) within the first year of follow up.
\end{abstract}

Conclusion: TCCAB is taking an increasing prominence relative to $S C C A B$ in the region. Effective treatment of bladder cancer is highly dependent on early presentation and diagnosis, and prevention entails prompt risk factor identification and intervention.

\section{Keywords}

Bladder cancer, Transitional cell cancer of the bladder, Squamous cell cancer of the bladder, Schistosomiasis

\section{Introduction}

Cancer of the bladder ( $C A B)$ is a common urological malignancy affecting the urothelium (transitional epithelial cells) that line the urinary bladder. It has one of the highest recurrence rates of any malignancy [1]. Worldwide, an estimated 336,000 cancer of the urinary bladder occur each year [2] with about 26,000 new cases in Africa alone [2]. CAB is the $4^{\text {th }}$ commonest malignancy in men [2], and second most common urological malignancy $(6.1 \%)$ after cancer of the prostate $[3,4]$, with worldwide mortality highest in north Africa due to the high incidence of schistosoma infestations [2]. Worldwide, there is a male to female ratio of $3: 1[4,5]$, with peak prevalence among 60-70 years [4]. In Africa, there is a considerable predominance of cancer of the bladder in men over women [2].

Globally, the commonest histological types seen are transitional cell cancer (urothelial cancer) (TCCAB) $(90 \%)[2,3]$ due to its strong association its environmental chemical carcinogens such as tobacco,

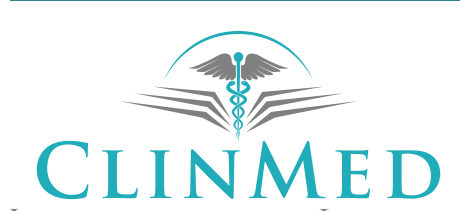

INTERNATIONAL LIBRARY 
and occupational exposure to polycyclic aromatic hydrocarbons [6] with squamous cell cancer of the bladder (SCCAB) constituting about 6\%. However, in schistosoma endemic African regions and the middle east, SCCAB still seems to be the more predominant pattern (as high as $80-90 \%$ in some areas) [7-9] due to lower levels of exposure to carcinogenic chemicals [1012] and the effect of chronic schistosoma infestation in squamous metaplasia of the normal transitional epithelium [13], with the incidence highest in Egypt [2]. Bladder cancer is infact the commonest malignancy amongst Egyptians (30.3\%) [6,14].

Studies done by Eni $U$, et al. in Maiduguri, north east Nigeria, Ochicha $\mathrm{O}$, in Kano and Mungadi I, in Jos showed SCCAB to be the most common histological type in north east, north west, and north central Nigeria respectively, accounting for 53-65.1\% $[3,15,16]$. Studies also done by Mbonu and Eni established a strong link between high schistosoma infestation and SCCAB $[8,17]$, in keeping with results of studies done in other African regions $[10,11,18]$.

Adult Schistosoma hematobium commonly invade the venous plexus within the urinary bladder and release its eggs which cause a chronic granulomatous inflammation in the mucosa and submucosa of the urinary bladder. This eventually leads to squamous metaplasia of the normal transitional epithelium. The chronic granulomatous inflammation also causes bladder fibrosis which reduces bladder compliance resulting in urine stasis and bacteria superinfection. This leads to chronic cystitis $[19,20]$ which is itself a risk factor for SCCAB. The bacteria also convert dietary nitrates and nitrites into nitrosamines which are carcinogenic. These carcinogens further act on the metaplastic epithelium, subsequently resulting in $\operatorname{SCCAB}[13,21]$. This is relatively commoner in paraplegics and chronic urinary tract infections. Other mechanisms include the elaboration of beta-glucuronidase by schistosoma ova which can deconjugate and activate carcinogenic metabolites in urine [15,22], and genetic damage [23,24].

The peak prevalence and intensity of early infection with vesical schistosomiasis occurs between ages 1020 , and declines by 65 years [25], thus accounting for why patients with $S C C A B$ tend to be much younger $(<50$ years) than those with TCCAB in such endemic regions. Studies put the mean age at diagnosis at $44-48$ years $[6,15]$ with majority being fishermen and farmers living in regions along rivers, while $50 \%$ of the cases were positive for schistosoma eggs $[2,6]$. Local studies in various regions in Nigeria have shown a predominantly male involvement with SCCAB accounting for up to 53$65.1 \%[15-17,26,27]$.

Other rarer histological patterns of bladder cancer include adenocarcinoma (commonly associated with metastasis, bladder exstrophy and persistent urachus), sarcoma (including rhabdomyosarcoma), small cell carcinoma, mixed carcinoma, lymphoma $[4,28]$.
In studies in West Africa, commonest presenting complaints were painless, total hematuria in $80-90 \%$ of patients [3], storage lower urinary tract symptoms (LUTS) [9], and features of metastases.

Risk factors that have been associated with TCCAB include tobacco smoking, which is the key contributor to TCCAB with cessation of smoking known to reduce its risk (2-naphthylamine, a carcinogen found in cigarette smoke has been shown to increase risk of bladder cancer) [4]. There is no known relationship between passive smoking and bladder cancer [29]. Other risk factors include hair dressers exposed to permanent hair dyes, shoe/leather workers, mechanics, bus drivers, and phenacetin abuse [30].

Known risk factors for SCCAB include chronic vesical schistosomiasis, recurrent bladder stones, bladder diverticulum, prolonged urethral catheterization, previous radiotherapy, use of cyclophosphamide, improper chronic exposure to fertilizers, and chronic cystitis [4].

The main objective of this study was to establish the relationship between demographics and histopathological patterns of bladder cancer and to elucidate some characteristics of histopathological patterns in this region.

\section{Patient and Methods}

This was a 5 year retrospective cohort study of all cases of histologically confirmed bladder cancer seen at the Alex Ekweme Federal Teaching Hospital, Abakaliki, a tertiary referral centre for south eastern and southern parts of the country, between 2011 and 2015. The study was carried out utilizing data from case notes and records from the surgical outpatient and casualty units of patients who had presented and were subsequently histologically confirmed to have bladder cancer. Demographic data including the age, sex, occupation, and residential city were obtained. The main presenting complaint, including time to presentation, as well as other associated symptoms and risk factors identified from clinical evaluation were identified. Results of diagnostic investigations including cystoscopy, abdominal ultrasound and histology, and subsequent treatment with or without recurrence or progression were also noted. The data was analyzed using OpenEpi info version 3.01. Frequency tables, percentages, pie charts and line diagrams were used. P-Value $<0.05$ was regarded as statistically significant.

\section{Results}

A total of 18 cases of histologically confirmed bladder cancer were reviewed-12 males (66.7\%) and 6 females $(33.3 \%)$, with a male to female ratio of $2: 1$. TCCAB accounted for 12 cases (66.7\%) while SCCAB accounted for 6 cases (33.3\%), giving a ratio of $2: 1$.

Those 60 years and above accounted for the highest 


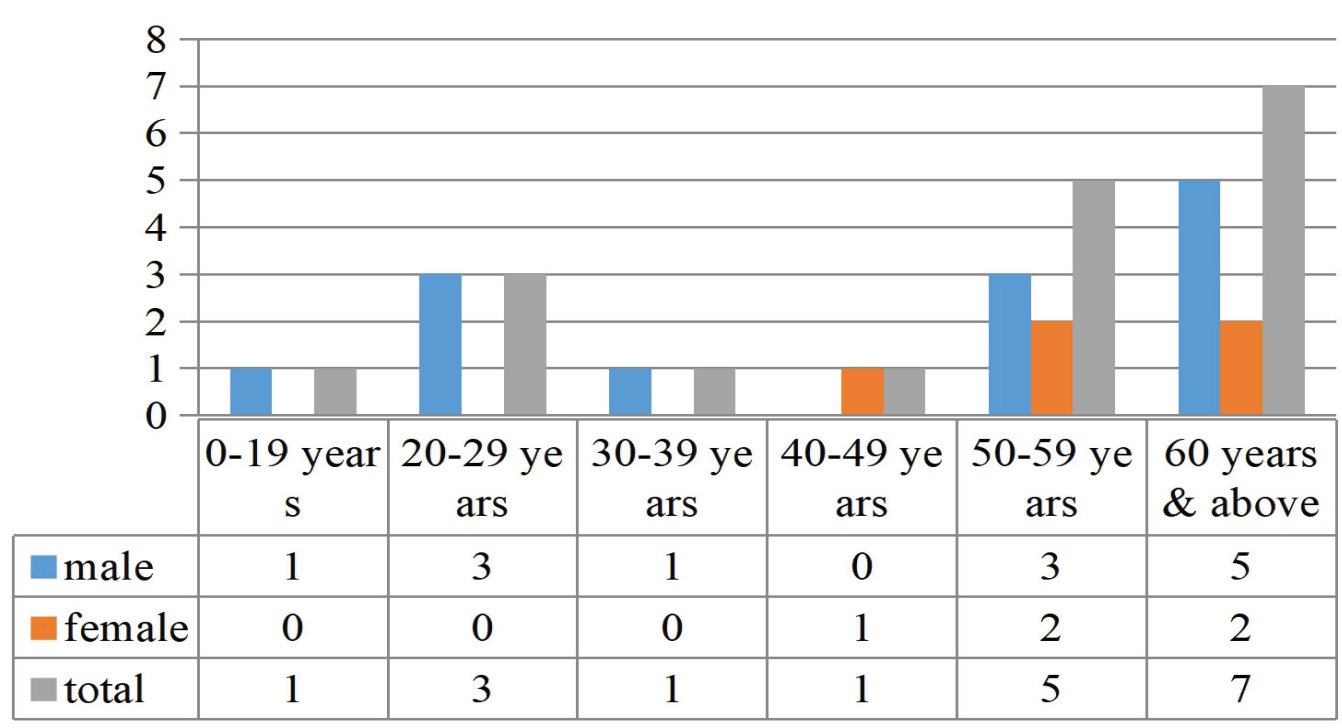

male

female

total

Figure 1: Age involvement in $C A B$.

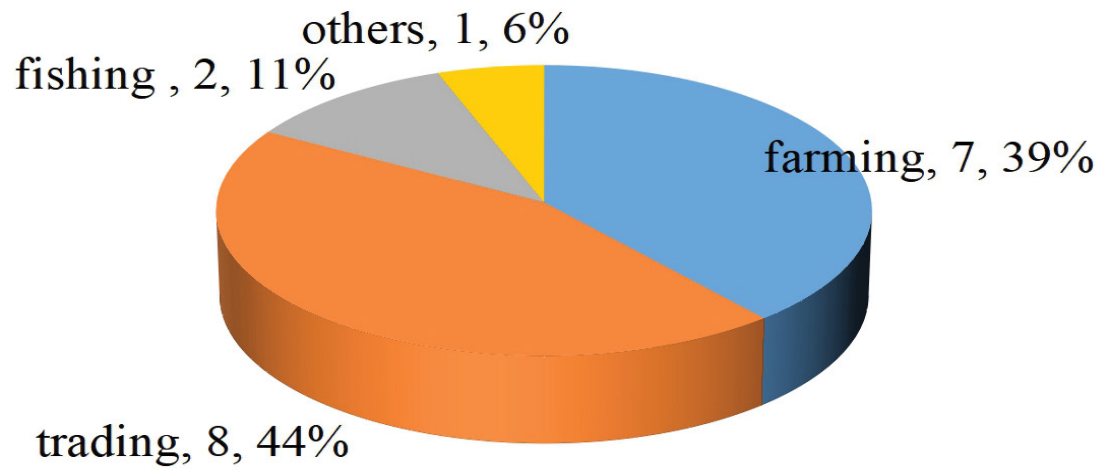

farming

trading

fishing

others

Figure 2: Occupational patterns.

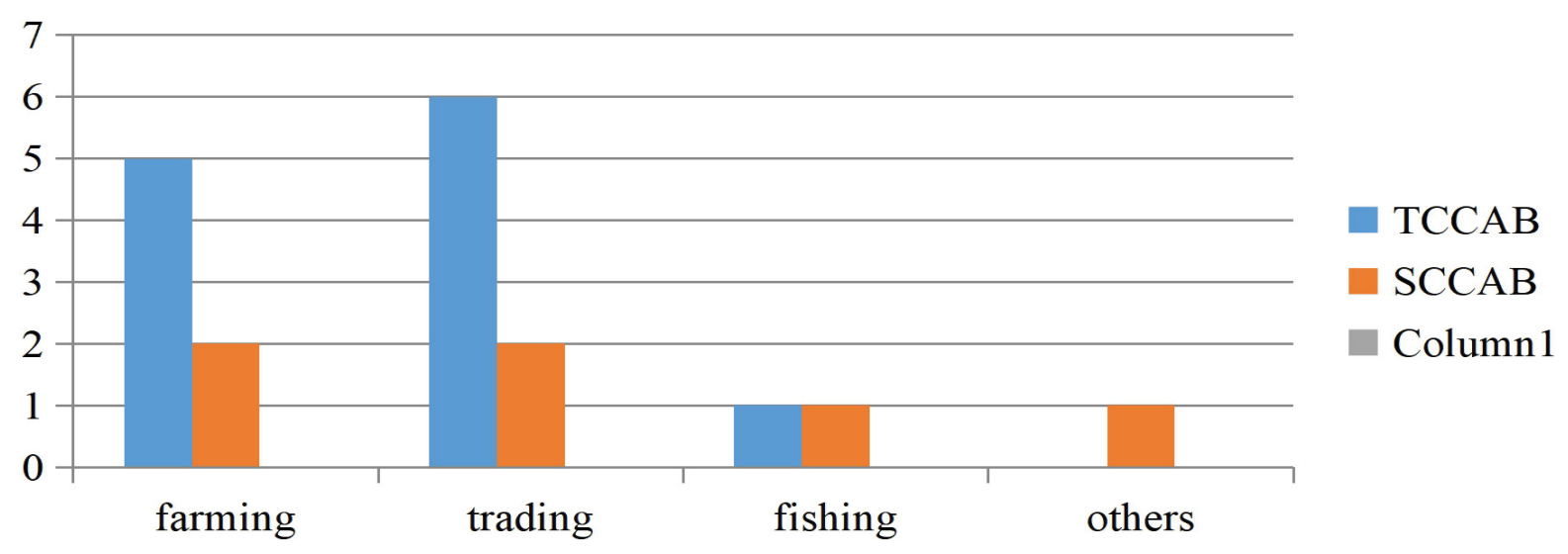

Figure 3: Histological patterns seen in various at risk occupations.

percentage of $C A B$, irrespective of the histologic type (Figure 1$)$. In the younger age groups ( $<50$ years) there was almost equal sex involvement, but above this group, more males than females tend to have CAB.

In terms of occupation, trading accounted for the highest percentage of those with $C A B(44 \%)$ with farmers having $39 \%$ (Figure 2 ).
The commonest histologic subtype, TCCAB, was seen in traders ( $50 \%$ of those who had TCCAB were traders) while the frequency of SCCAB in farmers and traders were equal (Figure 3 ).

In terms of age involvement via histologic subtype, SCCAB was most commonly seen in the young age group (20-29 years) while the incidence of TCCAB generally increased with age and reached its peak frequency in 


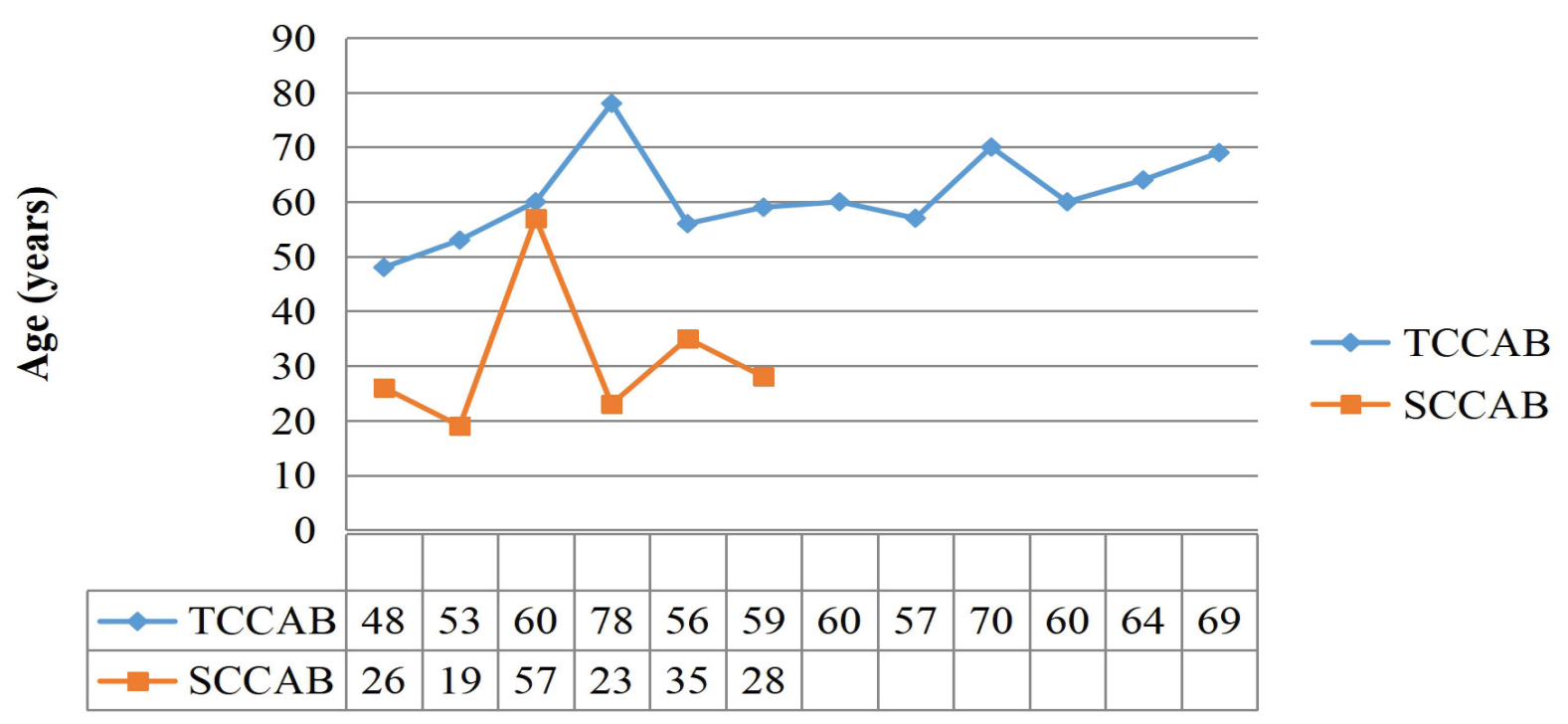

Figure 4: Histological patterns predominant in various age groups.

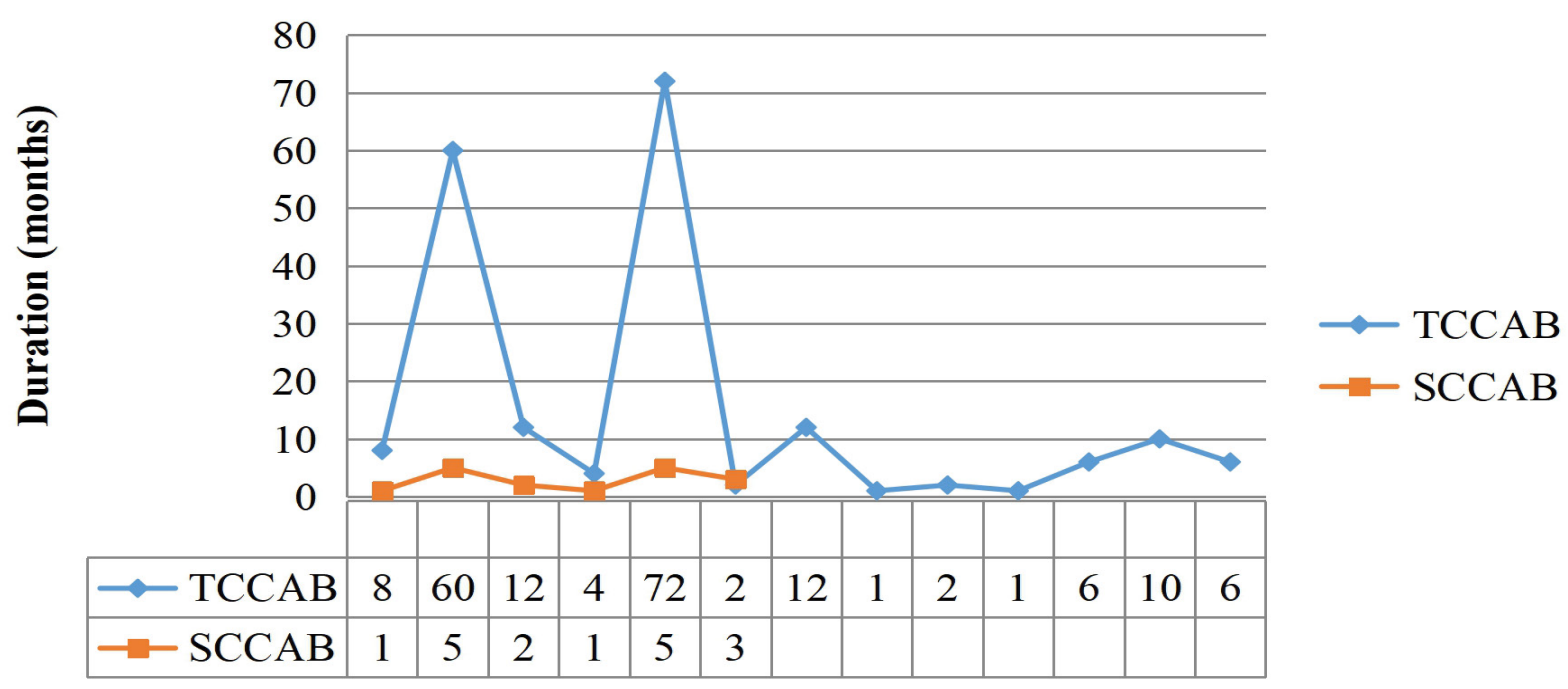

Figure 5: Time of onset to presentation (in months).

Table 1: Risk factors for various histologic patterns of $C A B$.

\begin{tabular}{|l|l|l|}
\hline \multicolumn{2}{|l|}{ TCCAB } & SCCAB \\
\hline Risk factors & $4(33.3 \%)$ & 0 \\
\hline Smoking & 0 & $3(50 \%)$ \\
\hline Schistosoma infestation & $1(8.3 \%)$ & 0 \\
\hline Snuff & 0 & $3(50 \%)$ \\
\hline Recurrent bladder stones & 1 (STAGE II) & 0 \\
\hline Recurrence & 0 & 0 \\
\hline Progression & & \\
\hline Stages & 1 & 0 \\
\hline Oa & 0 & 0 \\
\hline Ois & 7 & 1 \\
\hline I & 2 & 5 \\
\hline II & 0 & 0 \\
\hline III & 2 & 0 \\
\hline IV & 61.2 years & 31.3 years \\
\hline Av. age at diagnosis & & \\
\hline
\end{tabular}

the most elderly patients (> 60 years) (Figure 4 ). The average age at diagnosis was much higher for TCCAB (61.2 years) than for SCCAB (31.3 years) (Table 1 ).

The most frequent main presenting complaint of patients with $C A B$ was haematuria $(77.8 \%)$ while the commonest associated symptom was LUTS (77.8\%). LUTS (storage LUTS) was the main presenting complaint in only $22.2 \%$ of the patients with CAB (Table 2 ).

In terms of time to presentation at our facility from onset of symptoms, SCCAB had the earliest presentation of the two histologic subtypes seen. Patients who were eventually diagnosed with SCCAB had their earliest presentation at one month and latest presentation at five months with an average duration of presentation of 2 months 3 weeks (Table 3). Those with TCCAB had their earliest presentation at one month and latest presentation at 72 months (3 years) (Figure 5) with average duration of presentation at 17 months.

Majority of those with TCCAB presented at disease 


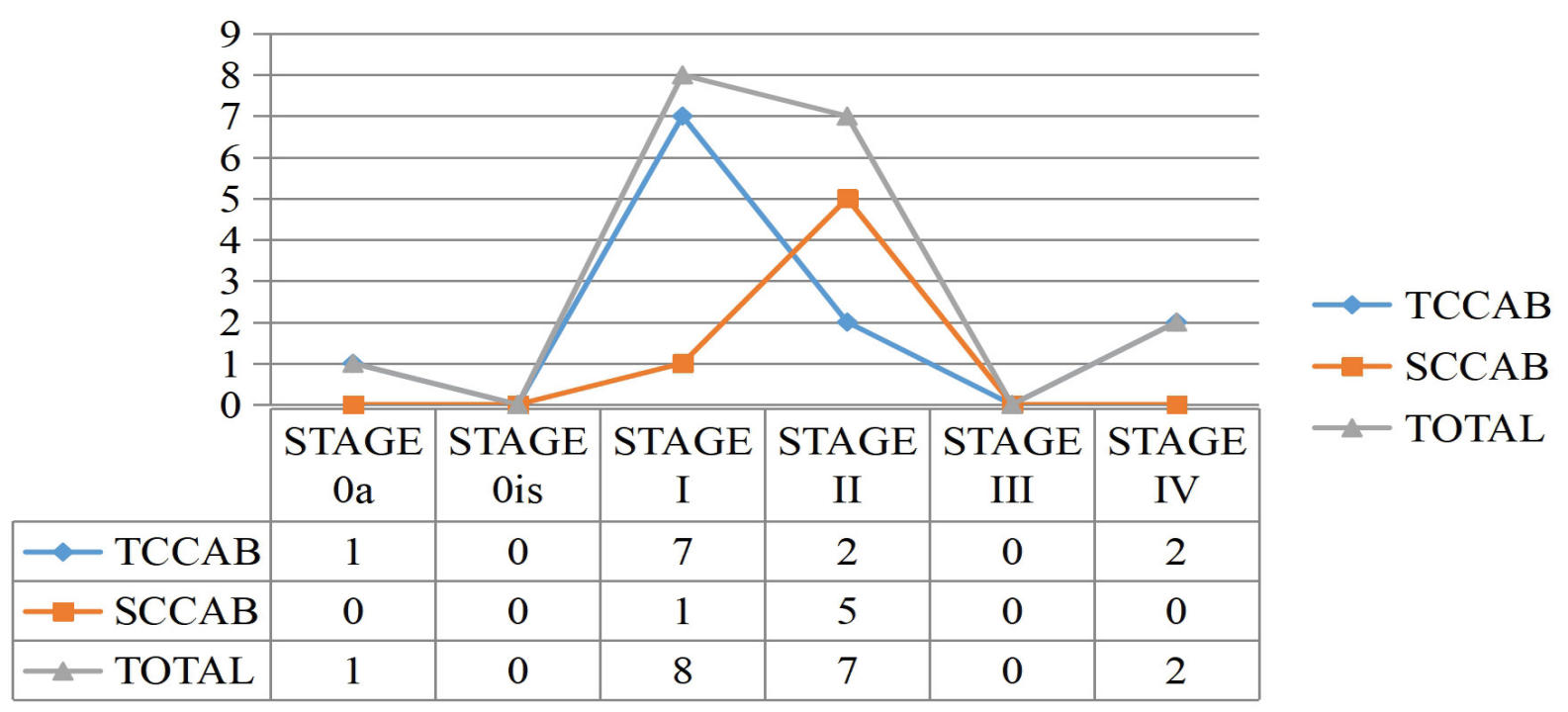

Figure 6: Disease stages in predominant histologic patterns.

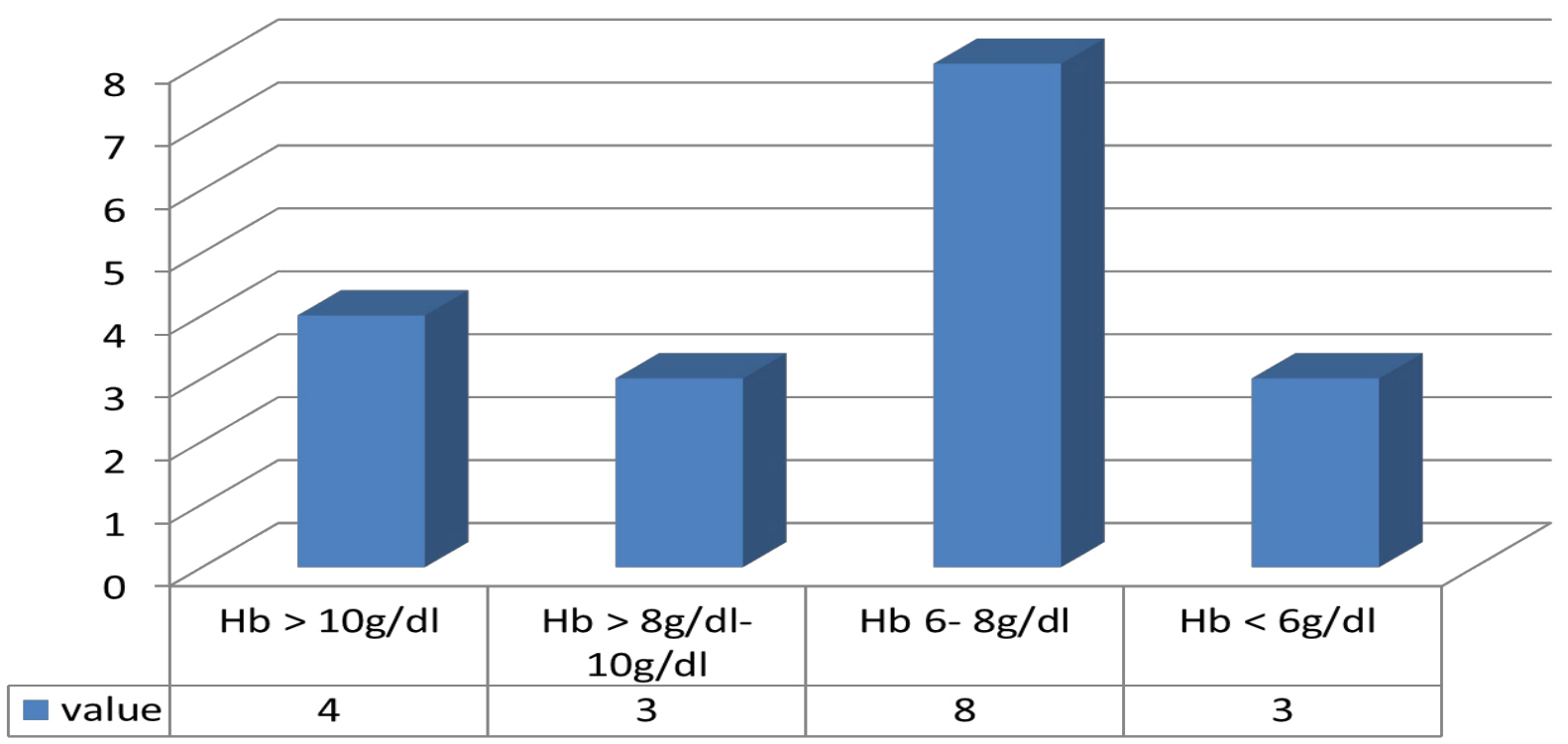

Figure 7: Haemoglobin at presentation.

Table 2: Clinical presentation.

\begin{tabular}{|l|l|l|}
\hline Hematuria & 14 & $77.8 \%$ \\
\hline Storage LUTS & 4 & $22.2 \%$ \\
\hline Voiding LUTS & 0 & $0 \%$ \\
\hline Associated symptoms & & \\
\hline Hematuria & 5 & \\
\hline LUTS & 14 & \\
\hline Metastases & 2 & \\
\hline
\end{tabular}

stage 1 (58.3\%) while majority of those with SCCAB presented at stage 2 (83.3\%) (Figure 6).

Majority of those with $C A B$ who presented had moderate anaemia (hemoglobin 6-8 g/dl) (44.4\%) (Figure 7).

Majority of the masses seen on abdominal ultrasound scan and cystoscopy were flat masses (61.1\%) (Table 4).
Table 3: Average duration before presentation.

\begin{tabular}{|l|l|}
\hline & Number (Months) \\
\hline TCCAB & 17 Months \\
\hline SCCAB & 2 Months 3 Weeks \\
\hline
\end{tabular}

Table 4: Abdominal ultrasound \& cystoscopy findings.

\begin{tabular}{|l|l|}
\hline Pedunculated soft tissue masses & Flat masses \\
\hline $7(38.9 \%)$ & $11(61.1 \%)$ \\
\hline
\end{tabular}

The risk factors seen in the patients with $C A B$ are shown in Table 1.

\section{Discussion}

In this study, males constituted a higher percentage of those affected by bladder cancer (66.7\%) with a male to female ratio of about 2:1. This was much lower than what had been obtained from previous studies 
in northern Nigeria and the Middle East (as high as 9-11.1:1) [9,16,31]. In south east Nigeria, there is an increasing female emancipation, and thus greater female involvement in activities which are male predominated in other parts of Nigeria and Africa, especially the north. Females are much more involved in fetching water from streams which are schistosoma infested. There is also greater liberalization of female involvement in what was hitherto considered male risk factors such as cigarette smoking and alcohol indulgence which carry heavy penalties in such regions where the ratio of sex involvement profoundly tilts in favour of males. A study in Tanzania in east Africa revealed a greater female involvement with bladder cancer (51.4\%) [6]. Thus culture and the degree of female emancipation may also play a crucial role in female involvement with bladder cancer. Also, predominance of farming as an occupation in eastern Nigeria with increased exposure to carcinogenic fertilizers, and with its improper use may also account for this observation.

The mean age at presentation in this study was 51.2 years, which was marginally higher than the mean of 44-48 years observed in local studies $[15,16]$. This is because TCCAB which predominate in older patients was the commonest histological type seen. However, SCCAB was the commonest type seen in patients $<50$ years, with a mean age of 31.3 years $(p<0.0001)$. This was in consonance with studies carried out by Thomas and Oyemenen in Ibadan [25], and Eni in Maiduguri [3]. Such young age group constitute the active work force of any nation, and their involvement could have a negative impact on any nation. The average age at diagnosis for TCCAB in this study was 61.2 years.

This study demonstrated a greater preponderance of TCCAB $(72.7 \%)$ relative to SCCAB $(27.3 \%)$. This may be attributed to the increased awareness and control of schistosoma infestations within the region, increased urbanization and risky practices such as cigarette smoking and inappropriate handling of fertilizers by farmers. Even among patients found to have SCCAB in this study, only $50 \%$ had a prior history suggestive of schistosoma infestation. The other $50 \%$ had a prior history of recurrent bladder stones. This may suggest a plummeting role of schistosoma as a causative factor for bladder cancer in the region with risk factors for TCCAB now beginning to play a more central role in bladder cancer.

The commonest presenting complaint was gross, painless haematuria with associated passage of blood clots (90\%). The average time from relative onset of the condition to first presentation at our facility in this study was 2 months and 3 weeks for SCCAB and 1 year 5 months for TCCAB. Majority of these SCCAB were stage II (muscle invasion) while majority of TCCAB were stage I (invasion of lamina propria/subepithelial connective tissue without muscle invasion). This reflects the relatively highly aggressive and invasive nature of SCCAB which had been attested to in a prior study [32]. SCCAB usually regarded as an aggressive cancer de novo, has a higher tendency for local invasion especially of the bladder wall musculature (one of the mechanisms for haematuria). TCCAB on the other hand has a preferential drive for spread through the blood stream and lymphatics than through local invasion, and is thus associated with higher frequency of early metastasis and pelvic lymph node involvement than local symptoms seen with SCCAB. In this study, the only cases of metastases (stage IV) were seen in patients with TCCAB. Infact, the average time from onset to first diagnosis of metastasis was only 4 months in such patients, further buttressing the fact that TCCAB will more likely directly metastasize without first undergoing local invasion. Local invasion with TCCAB is usually late. Thus, because of the more locally aggressive behaviour of SCCAB, such patients with SCCAB will tend to present to hospital earlier than those with TCCAB (where haematuria might be a late symptom).

Majority of the patients in this study had anaemia of varying degrees at first presentation $(\mathrm{Hb}<10 \mathrm{~g} / \mathrm{dl})$ (77.8\%). This also is in keeping with the commonest presenting symptom of haematuria.

Tumour recurrence (defined as a relapse of primary bladder cancer with either equivalent or lower pathological stage) was seen in one patient at stage II. Tumour progression (defined as a relapse with a higher TNM stage or grade) was absent.

\section{Recommendations}

Much effort should be focused at reducing risk factors for TCCAB through awareness campaigns and mass education on proper handling of fertilizers, use of PPEs for protection and controlled exposure.

\section{Conclusion}

TCCAB is taking an increasing prominence relative to SCCAB in this region. Better control of schistosoma infestations and increasing urban to rural ratio and industrialization with its attendant risk factors for TCCAB have contributed in no small measure to this trend. Prevention of $C A B$ entails prompt identification of indicted risk factors with appropriate control and intervention. Effective treatment is highly dependent on prevention and early diagnosis.

\section{References}

1. Thomas WF, Philippe ES, Neeraj A, Rick B, Stephen AB, et al. (2018) NCCN Guidelines insights: Bladder cancer, Version 5.2018. J Natl Compr Canc Netw 16: 1041-1053.

2. International Agency for research on cancer.

3. Eni U, Na'aya A, Ngadda H, Dogo D (2007) Carcinoma of the urinary bladder in maiduguri: The schistosomiasis connection. TIJO 5: 2.

4. Klufio GO, Yeboah ED (1986) Tumours of the bladder. In: 
Badoe EA, Archampong EQ, da Rocha Afodu JT, Principles and practice of surgery including pathology in the tropics. ( $4^{\text {th }}$ edn), TEMA: Ghana Publishing Corporation, Ghana, 874-880.

5. Johansson SL, Cohen SM (1997) Epidemiology and aetiology of bladder cancer. Semin Surg Oncol 13: 291-298.

6. Rambau PF, Chalya PL, Jackson K (2013) Schistosomiasis and urinary bladder cancer in North Western Tanzania: A retrospective review of 185 patients. Infect Agent Cancer 8: 19.

7. Heyns CF, Van der Merwe A (2008) Bladder cancer in Africa. Can J Urol 15: 3899-3908.

8. World Health Organization (1993) The control of Schistosomiasis.

9. Diao B, Amath T, Fall B, Fall PA, Diémé MJ, et al. (2008) Bladder cancers in Senegal: Epidemiological, clinical and histological features. Prog Urol 18: 445-448.

10. Abol Enein H (2008) Infection: Is it a cause of bladder cancer? Scand J Urol Nephrol 218: 79-84.

11. El Mawla NG, El Bolkainy MN, Khaled HM (2001) Bladder cancer in Africa: Update. Semin Oncol 28: 174-178.

12. Fedewa SA, Soliman AS, Ismail K, Hablas A, Seifeldin IA, et al. (2009) Incidence analyses of bladder cancer in the Nile delta region of Egypt. Cancer Epidemiol 33: 176-181.

13. Sheweita SA, El Shahat FG, Bazeed MA, Abu El Maati MR, O'Connor PJ (2004) Effects of schistosoma haematobium infection on drug-metabolizing enzymes in human bladder cancer tissues. Cancer Lett 205: 15-21.

14. Tawfik HN (1987) Carcinoma of the urinary bladder associated with schistosomiasis in Egypt: The possibly causal relationship. Princess Takamatsu Symp 18: 197209.

15. Ochicha O, Alhassan S, Mohammed AZ, Edino ST, Nwokedi EE (2003) Bladder cancer in Kano: A histopathological review. West Afr J Med 22: 202-204.

16. Mungadi IA, Malami SA (2007) Urinary bladder cancer and schistosomiasis in North-Western Nigeria. West Afr J Med 26: 226-229.

17. Aghaji AE, Mbonu OO (1989) Bladder tumours in Enugu, Nigeria. BJU 64: 399-402.

18. Attah EB, Nkposong EO (1976) Schistosomiasis and carcinoma of the bladder. A critical appraisal of casual relationship. Trop Geog Med 28: 268-272.
19. Lehman JS, Farid Z, Smith JH, Bassily S, EI Masry NA (1973) Urinary schistosomiasis in Egypt: Clinical, radiological, bacteriological and parasitological correlations. Trans $R$ Soc Trop Med Hyg 7: 384-399.

20. Laughlin LW, Farid Z, Mansour N, Edman DC, Higashi GI (1978) Bacteriuria in urinary schistosomiasis in Egypt. A prevalence survey. Am J Trop Med Hyg 27: 916-918.

21. Barsoum RS (2003) Schistosomiasis and the kidney. Semin Nephrol 23: 34-41.

22. Fripp PJ (1965) Bilharziasis and bladder cancer. Brl Can 19: 292-296.

23. Shubber EK (1987) Sister-chromatid exchanges in lymphocytes from patients with schistosoma hematobium. Mutat Res 180: 93-99.

24. Habuchi T, Takahashi R, Yamada H, Ogawa O, Kakehi $Y$, et al. (1993) Influence of cigarette smoking and schistosomiasis on p53 gene mutation in urothelial cancer. Cancer Res 53: 3795-3799.

25. Fulford AJ, Webster M, Ouma JH, Kimani G, Dunne DW (1998) Puberty and age-related changes in susceptibility to schistosome infection. Parasitol Today 14: 23-26.

26. Mandong BM (1997) Carcinoma of the urinary bladder in Jos, Nigeria. Nig Med Pract 33: 33-34.

27. Thomas JO, Onyemenen NT (1995) Bladder carcinoma in Ibadan, Nigeria: A changing trend? East Afr Med J 72: 4950 .

28. Jacobo E, Loening S, Schmidt JD, Culp DA (1977) Primary adenocarcinoma of the bladder: A retrospective study of 20 patients. J Urol 117: 54-56.

29. Zeegers MP, Goldbohm RA, Van Den Brandt PA (2002) A prospective study on active and environmental tobacco smoking and bladder cancer risk. Cancer Causes Control 13: 83-90.

30. Raoul CR, Eliane K, Frank B, Maree B, Maurice PZ (2008) A meta-analysis on the association between bladder cancer and occupation. Scand J Urol Nephrol 42: 64-78.

31. Khurana P, Morad N, Khan AR, Shetty S, Ibrahim A, et al. (1992) Impact of schistosomiasis on urinary bladder cancer in the southern province of Saudi Arabia: review of 60 cases. J Trop Med Hyg 95: 149-151.

32. Badr KM, Nolen JD, Derose PB, Cohen C (2004) Muscle invasive schistosomal squamous cell carcinoma of the urinary bladder: Frequency and prognostic significance of p53, BCL-2, HER2/neu, and proliferation (MIB-1). Hum Pathol 35: 184-189. 